\title{
Dilemas da política científica da Educação Física brasileira em tempos de produtivismo acadêmico
}

\author{
Régis Henrique dos Reis Silva* \\ Michele Silva Sacardo** \\ Wilson Luis de Souza***
}

\begin{abstract}
Resumo: A pretensão deste ensaio é discutir sucintamente os dilemas da política científica da Educação Física brasileira em tempos de produtivismo acadêmico, particularmente a que se desenvolve no âmbito da pós-graduação stricto sensu. A partir da análise do panorama da pós-graduação brasileira, visualizamos o processo de reconfiguração da Capes e da Universidade brasileira nos últimos anos, no qual destacamos os indicadores "otimistas" da política científica dos Programas de Pós-Graduação em Educação Física - PPGEF, como também os aspectos preocupantes para a área. Diante desse quadro e no intuito de instigar o debate, apontamos então algumas possibilidades existentes na Educação Física.
\end{abstract}

Palavras-chave: Política científica. Educação Física. Produtivismo acadêmico.

\section{ApresentaçÃo}

Ao investigarmos a produção do conhecimento em Educação Física, mais especificamente aquela desenvolvida na pós-graduação stricto sensu brasileira, temos observado que a reconfiguração da Coordenadoria de Aperfeiçoamento de Pessoal de Nível Superior (CAPES) e da Universidade brasileira nos últimos anos, principalmente a lógica de avaliação assumida pela primeira, possui notória influência no processo que norteia e direciona os dilemas alavancados na política científica da Educação Física.

\footnotetext{
$\overline{{ }^{7} F a c u l d a d e ~ d e ~ E d u c a c ̧ a ̃ o ~ F i ́ s i c a, ~ U n i v e r s i d a d e ~ F e d e r a l ~ d e ~ G o i a ́ s, ~ G o i a ̂ n i a, ~ G O, ~ B r a s i l . ~ E-m a i l: ~}$ regishsilva@bol.com.br

"Cursos de Educação Educação Física; Programa de Pós-Graduação em Educação (PPGE) - Regional Jataí /Universidade Federal de Goiás (UFG), Jataí, GO, Brasil. email: michelesacardo@hotmail.com.

"*Faculdade de Educação Física, Regional Goiânia, Universidade Federal de Goiás (UFG), Goiânia, GO, Brasil. E-mail: wilson_lino@uol.com.br.
} 
Assim sendo, neste ensaio não temos a pretensão de abranger todos os aspectos relacionados à pós-graduação, e nem de esgotar esta discussão, mas, sim, provocá-la sobre alguns aspectos desta prática.

Para tanto, primeiramente trataremos do processo de reconfiguração da CAPES e da Universidade brasileira ocorrida nos últimos 20 anos. Em seguida, abordaremos mais especificamente a política científica da Educação Física mediada pelos Programas de Pós-Graduação em Educação Física (PPGEF) via área 21. Por fim, apresentaremos os dilemas ${ }^{1}$ da política científica da Educação Física diante do quadro mais geral da pós-graduação no Brasil, e mais precisamente das áreas 21 (Saúde/Educação Física), 38 (Humanas/Educação) e/ou 46 (Multidisciplinar/Ensino) ${ }^{2}$.

\section{Notas sobre o processo de ReConfiguraçÃo dA CAPES E DA UNIVERSIDADE BRASILEIRA}

A política de pós-graduação na Educação Física em tempos de produtivismo acadêmico precisa ser analisada no contexto de reconfiguração da CAPES e da Universidade brasileira ocorrida nos últimos 20 anos.

Nesse sentido, os condicionantes sociais, políticos e econômicos são determinantes para os rumos da política científica

\footnotetext{
'DILEMA, conforme Lalande (1999, p. 260), significa: raciocínio de que uma premissa contém uma alternativa com dois termos, e cujas outras premissas mostram que os dois casos da alternativa implicam a mesma consequência. [...] Mas, geralmente, chama-se dilema todo raciocínio do mesmo tipo em que a alternativa compreende mais de dois casos [...]. Com sentido semelhante, mas explicitando mais claramente o significado que atribuímos ao termo dilema, encontramos, no dicionário Aurélio Buarque de Hollanda Ferreira (2010), a seguinte definição: dilema, do latim dilemma, significa situação difícil, na qual é preciso escolher entre duas alternativas contraditórias ou antagônicas ou insatisfatórias. No nosso caso, dilema significa: situação difícil, na qual é preciso escolher entre duas ou mais alternativas insatisfatórias, pois, como veremos na sequência, a opção por qualquer uma delas, embora tenha implicações distintas, não equaciona substancialmente o sentido do fazer científico na pós-graduação brasileira neste início de século XXI.

\begin{abstract}
${ }^{2} \mathrm{Não}$ obstante, as referidas áreas não romperem substancialmente com o produtivismo acadêmico e o perfil epistemológico da produção científica deste início de século, como o predomínio do realismo empírico (ÁVILA, 2008) em um contexto de "lluminismo às avessas" e "Mundialização do Capital", como diriam, respectivamente, Moraes (2001) e Chesnais (2005). É necessário reconhecermos que, nas referidas áreas, os critérios de avaliação da produção são distintos, e consequentemente, suas implicações e desdobramentos do fazer científico também são, especialmente a exigência de produtos (artigos) e de internacionalização da produção.
\end{abstract}

Movimento, Porto Alegre, v. 20, n. 4, p. 1563-1585, out./dez. de 2014. 
brasileira, uma vez que a crise do capital gerou mudanças no sistema do capital e no seu metabolismo social, nas diferentes esferas sociais, em especial na produtiva (reconversão produtiva), na política (neoliberalismo) e na ideológica ("recuo da teoria" hegemonia do realismo empírico); sem deixar de mencionar o projeto educativo proposto nos fóruns de governança global.

Assim, em virtude do caráter associado-dependente do modo de inserção do Brasil no sistema do capital, as referidas mudanças começaram a ocorrer de forma mais incisiva em nosso país nos últimos 25 anos, aproximadamente, quando a organização social brasileira iniciou um processo de profundas transformações políticas, econômicas e sociais.

É interessante observar que, de 1990 em diante, foi marcante o processo de fortalecimento institucional da CAPES, que, graças ao crescimento significativo do seu orçamento e atribuições (poderes), passou a gerenciar os programas de pós-graduação e a ditar os rumos da "Formação para o Trabalho Complexo no Brasil Contemporâneo" (NEVES; PRONKO, 2008), sob a concepção produtivista de Educação.

Nesse mesmo período, a Universidade brasileira foi reconfigurada por políticas que alteraram a sua lógica de financiamento (diversificação das fontes) e funcionamento (ethos neodarwinista), transformando-a mais em centro administrativo do que intelectual (MORAES, 2004) e tornando-a uma instituição de caráter operacional, próprio do Estado empresarial, conforme preconizara Chauí (2003).

Dessa forma, a lógica da avaliação diante da constituição de um ethos neodarwinista na Universidade brasileira, a partir do modelo definido pela CAPES para gerir o Sistema Nacional de Pós-Graduação (SNPG), foi a constituição do binômio avaliação-fomento e o estímulo à competição. Para tanto, fundamentou o modelo avaliativo em bases quantitativas e em uma concepção de ciência universal ${ }^{3}$ (VELHO,

${ }^{3}$ Sobre essa discussão, particularmente a respeito do processo em que diferentes países, inclusive o Brasil, adotam as mesmas visões de Políticas de Ciência, Tecnologia e Inovação (PCTI), assim como instrumentos e formas semelhantes de gestão da PCTI, sugerimos a leitura de Velho (2011).

Movimento, Porto Alegre, v. 20, n. 4, p. 1565-1587, out./dez. de 2014. 
2011), pois a finalidade era inserir o Brasil no sistema mundial de produção científica (OURIQUES, 2011) .

$\mathrm{Na}$ Educação Física, Bracht (2006) fez referência ao privilegiamento do "periodismo" a outras formas de produção e veiculação do conhecimento. Também acrescentaríamos outras atividades desenvolvidas pelo professor/pesquisador que são fundamentais para o desenvolvimento das áreas de conhecimento, e que ainda não são devidamente valorizadas pelo sistema CAPES de avaliação.

Nesse contexto, o novo "paradigma" de avaliação dos programas de pós-graduação implementados pela CAPES a partir da segunda metade dos anos 1990 alterou a centralidade da pósgraduação da docência para a pesquisa. Essa alteração, ao mesmo tempo em que contribuiu para que as atividades desse setor assumissem um caráter mais científico, também colaborou para um "verdadeiro surto produtivista em que o que conta é publicar" (KUENZER; MORAES, 2005, p. 1348). Isso porque só se avalia o que é mensurado.

Durante esse processo, a CAPES sempre esteve atenta aos dois objetivos principais da pós-graduação, a saber: 1) a formação de recursos humanos (professores/pesquisadores para atuar no ensino superior; técnicos e gestores públicos para atuar na administração pública; e quadros técnicos para atuarem nas empresas); e 2) a produção do conhecimento em termos quantitativos, por isso a importância dos Tempos Médios de Titulação (TMT) ${ }^{5}$ e a avaliação da produção intelectual.

Nesse sentido, embora os principais dirigentes da Ciência, Tecnologia \& Inovação (CTI) no Brasil reconheçam os baixos e preocupantes índices de inovação do Sistema Nacional de CTI,

${ }^{4} \mathrm{O}$ texto do Nildo Ouriques é fundamental para se compreender a função de um país periférico como o Brasil nesse sistema, e também a natureza da "produção científica" que vem sendo realizada no nosso país.

${ }^{5}$ Conforme apresentado no relatório do Seminário de Acompanhamento da Área 21, realizado em Brasília, em dezembro de 2012, o TMT do mestrado em EF é 25,16 meses e do doutorado é 39,47 meses, no triênio de 2010/2012.

Movimento, Porto Alegre, v. 20, n. 4, p. 1563-1585, out./dez. de 2014. 
principalmente em relação à pouca repercussão internacional dos artigos científicos brasileiros ${ }^{6}$, reiteram que o projeto empreendido pela CAPES é exitoso, pois, conforme apresentado no Plano Nacional de Pós-Graduação para o período de 2011 a 2020 (PNPG/2011-2020), a produção acadêmica brasileira já ocupa a $13^{\mathrm{a}}$ posição no Institute for Scientific Information (ISI) e a $14^{\mathrm{a}}$ no Open to Accelerate Science (SCOPUS) em termos de número de artigos publicados, representando $2,6 \%$ da produção científica mundial ${ }^{7}$. Em relação ao índice de citações, o Brasil ocupa a $35^{\mathrm{a}}$ posição.

Sobre esse projeto, é pertinente destacar que a CAPES, a partir do segundo ciclo dos PNPG (2005 em diante), passa a trabalhar com o princípio da indução, o qual pode ser observado em uma série de ações desenvolvidas por ela e outras agências de fomento no Brasil. Estas estão em consonância com a perspectiva da pesquisa instrumental, estabelecem uma agenda pragmático-inovativa para as investigações realizadas em parceria com as empresas, e uma agenda pragmático-social para as pesquisas que apoiem e/ou retroalimentem as políticas de governo, seja em âmbito municipal, estadual e/ou federal. A primeira vem afetando, sobretudo, as áreas das exatas, agrárias, biológicas, parte da saúde etc., e a segunda vem influindo, principalmente, nas áreas das humanas e sociais ${ }^{8}$.

Nesse processo, dentre os eixos estratégicos dos dois últimos PNPG (2005-2010 e 2011-2020) que vêm sendo objeto de indução

\footnotetext{
${ }^{6}$ Durante a $65^{a}$ Reunião Anual da Sociedade Brasileira para o Progresso da Ciência (SBPC), em Recife (PE), os participantes da mesa-redonda "Impacto e avaliação da pesquisa", Carlos Henrique de Brito Cruz, diretor científico da FAPESP, Glaucius Oliva, presidente do CNPq, e Jorge Almeida Guimarães, presidente da CAPES apontaram que um dos fatores responsáveis pelo baixo impacto da ciência feita no Brasil é a pouca cooperação de cientistas brasileiros com pesquisadores do exterior. Segundo dados apresentados pelo diretor científico da FAPESP, nos últimos anos diminuiu muito a cooperação internacional dos cientistas brasileiros, evidenciada pela queda de $40 \%$ para $27 \%$ da publicação de trabalhos em coautoria. Algumas medidas foram sugeridas para alterar o quadro, dentre elas destacamos: a) aumentar a cooperação internacional, a visibilidade e o impacto das revistas científicas publicadas pelo Brasil - uma vez que $33 \%$ dos artigos científicos de autores brasileiros saem em periódicos nacionais e, b) valorizar a qualidade, em detrimento da quantidade, dos artigos científicos publicados por pesquisadores na análise de seus projetos de pesquisa na hora de conceder financiamento ou na promoção de cargo, entre outras situações (AGÊNCIA FAPESP, 2013).

${ }^{7} I S I$ e SCOPUS são bases de dados que informam a posição dos países na produção cientíica mundial (número de artigos publicados em revistas indexadas internacionalmente nessas duas bases de dados).
}

${ }^{8}$ Maiores detalhes consultar Silva (2013).

Movimento, Porto Alegre, v. 20, n. 4, p. 1565-1587, out./dez. de 2014. 
da CAPES e que guardam relação com a constituição histórica da Educação Física brasileira, destacamos a Educação Básica, pois, assim como Bracht (2006) e Sánchez Gamboa (2007), entendemos que a Educação Física vem se constituindo historicamente como Educação. Mais especificamente como intenção pedagógica para o primeiro autor, e, para o segundo, como ato pedagógico. Portanto, é oportuno destacar a criação, no âmbito da CAPES, das Diretorias de Educação Básica Presencial (DEB) e de Educação a Distância (DED), assim como os desdobramentos dessas ações na Universidade brasileira, a partir da observação dos vários programas em execução, como Programa Institucional de Bolsa de Iniciação à Docência (PIBID), Programa de Consolidação das Licenciaturas (Prodocência), Plano Nacional de Formação de Professores da Educação Básica (Parfor), Novos Talentos, Programa de Apoio a Laboratórios Interdisciplinares de Formação de Educadores (LIFE), Licenciaturas Internacionais e, por último, a criação da área de Ensino - o que temos nomeado de "PACOTE CAPES PARA A EDUCAÇÃO BÁSICA BRASILEIRA".

Não obstante, como observa Moraes (2006), entre acontecimentos político-econômicos e a produção intelectual e artística, há uma relação de mediações e condicionantes, logo não é causal e direta. Portanto, entre as áreas que compõem o SNPG, esses condicionantes também não têm uma relação causal e direta. Por isso, na sequência apresentamos alguns indicadores da política científica dos PPGEF (via área 21) para a EF brasileira em tempos de produtivismo acadêmico.

\section{A política científica da Educação Físıca (VIa Área 21) EM TEMPOS DE PRODUTIVISMO ACADÊMICO}

A partir desse panorama da pós-graduação brasileira, a política científica dos PPGEF (via área 21) em tempos de produtivismo acadêmico tem apresentado indicadores "otimistas" e preocupantes para a área.

Sobre os aspectos "otimistas" da área, podemos destacar o desenvolvimento dos PPGEF nos últimos 20 anos, principalmente a expansão no número de programas de pós-graduação, o número

Movimento, Porto Alegre, v. 20, n. 4, p. 1563-1585, out./dez. de 2014. 
Dilemas da política científica da Educação Física ...

de mestres e doutores titulados, o aumento na produção científica da área e o crescimento no índice de impacto da área.

As figuras a seguir evidenciam tais evoluções. A primeira demonstra a evolução dos programas por períodos e níveis. A segunda apresenta o número de mestres e doutores titulados por nível e períodos:

Figura 1 - Demonstrativo da evolução do número de PPGEF, por nível e períodos ${ }^{9}$.

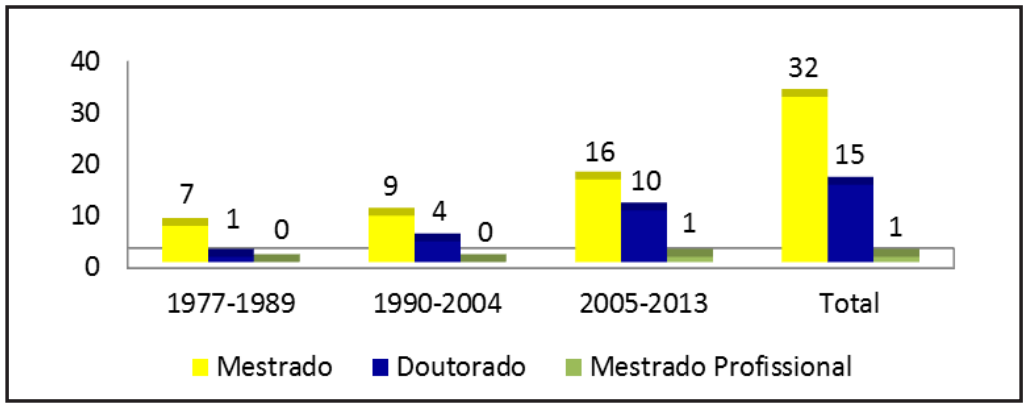

Fonte: Silva (2013).

Conforme a figura 1, podemos observar que ao longo de 36 anos foram criados pela área 32 Programas de Mestrado, 15 de Doutorado e 1 Mestrado Profissional, sendo que o aumento significativo do número de programas ocorreu após 2004.

Vejamos que o crescimento dos PPGEF mais que dobrou em um período que levou 25 anos (1977 a 2004) para se constituir. Já em um curto período de nove anos (2004 - 2013), houve um verdadeiro "boom" de programas.

\footnotetext{
$9^{*}$ UFSM e UFRJ: são programas que funcionaram de 1979 a 2002, aproximadamente, depois ficaram desativados por um período e retomaram suas atividades em 2009 (UFRJ) e em 2011 (UFSM).

"UERJ, UCB/RJ - O programa da UCB/RJ funcionou de 1992 a 2002, e o da UERJ há registros de defesas em 1995 e 1996, aproximadamente, depois ambos foram desativados e não retomaram mais suas atividades.

"'Não contabilizamos: Fonoaudiologia (UNESP/MAR); Reabilitação e Desempenho Funcional (USP/RP); e Terapia Ocupacional (UFSCAR).
}

Movimento, Porto Alegre, v. 20, n. 4, p. 1565-1587, out./dez. de 2014. 
De fato, antes deste curto período já se configurava o contexto do redesenho da pós-graduação brasileira (1995 a 2003) no sentido de atender ao ajuste neoliberal do Estado brasileiro via um conjunto de medidas e ações implantadas pela CAPES, dentre as quais se destacam a criação do mestrado profissionalizante (atual mestrado profissional) e a mudança no paradigma de avaliação dos programas.

Figura 2 - Demonstrativo do número de mestres e doutores titulados nos PPGEF brasileiros por nível e períodos

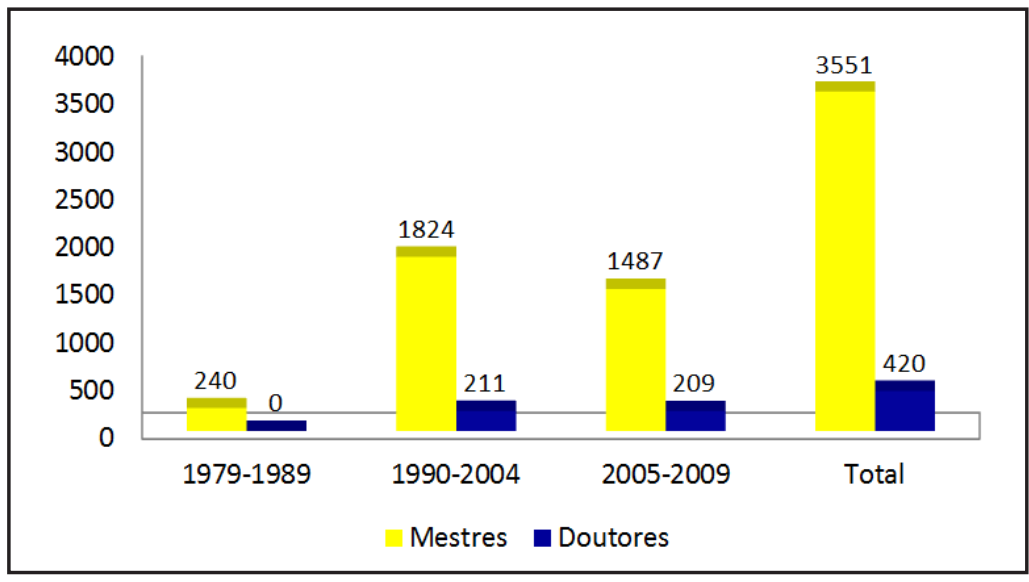

Fonte: Silva (2013).

Pela figura 2, notamos que até 2009 já existiam 3551 mestres e 420 doutores titulados, isto sem contar os inúmeros professores/ pesquisadores da área de Educação Física que optaram em fazer seu mestrado e doutorado em outros programas, principalmente na área de Educação, uma vez que os programas da Educação Física existentes não contemplavam seus interesses políticoepistemológicos para a produção de conhecimento.

Dessa forma, tal expansão e concentração podem ser explicadas por duas situações: 1) em função dos próprios reflexos das políticas de pós-graduação e os seus critérios de avaliação, que, dentre outros, ao diminuírem o tempo de titulação, consequentemente aumentaram a rotatividade de alunos nos programas e suas 
respectivas produções científicas; 2) ao crescimento vigoroso da pós-graduação da área 21, principalmente na Educação Física.

Nessa perspectiva, é mais intensamente na vigência do PNPG/2005-2010 que correspondeu o maior volume de dissertações e teses produzidas, e mestres e doutores titulados em um contexto em que as medidas norteadoras estavam regidas nos princípios de "flexibilização, competitividade e elevação dos padrões nacionais a padrões internacionais" (ÁVILA, 2008, p. 84). Com isso, a finalidade principal da pós-graduação recai sobre a produção do conhecimento e a formação de pesquisadores, com ênfase avaliativa sobre os produtos, no caso a produção bibliográfica qualificada.

Assim, a valorização da produtividade acarretou a "corrida desenfreada" para a quantidade de produtos publicados e esses têm trazido consequências do tipo: a) a quantificação no campo da pesquisa apresenta maiores resistências em relação a outros, já que a qualidade da produção não pode ser facilmente mensurável; b) ao publicar demasiadamente corre-se o risco de produzir trabalhos sem aprofundamento teórico e qualidade; c) a diminuição do tempo para a titulação afeta tanto a qualidade da formação dos estudantes quanto a qualidade das dissertações no mestrado (KUENZER; MORAES, 2005).

Além disso, conforme apresentado no relatório do Seminário de Acompanhamento da Área 21, realizado em Brasília, em dezembro de 2012, existem 1623 periódicos no Webqualis da área, e esta sinaliza para a manutenção do qualis e a regra do CTC da Diretoria de Avaliação da CAPES, a saber: A1 < A2; A1 + A2 $\leq 25 \%$; e A $1+$ $\mathrm{A} 2+\mathrm{B} 1 \leq 50 \%$. Quanto aos livros, o mesmo documento informa que os programas estão aperfeiçoando a submissão. Mas em junho de 2011, conforme Documento Balanço do triênio 2007/2010, 50\% dos livros enviados para avaliação não eram classificados. A respeito da produção intelectual (esta representa aproximadamente $70 \%$ da avaliação do programa - envolve a produção do corpo discente e docente $-40 \%$ ), o referido documento destaca o crescimento excepcional desse item da avaliação chamando a atenção para o fato de que, em comparação com o triênio anterior, a média e a

Movimento, Porto Alegre, v. 20, n. 4, p. 1565-1587, out./dez. de 2014. 
mediana aumentaram $60 \%$ e $58 \%$, respectivamente. A expectativa da mediana para o triênio 2010/2012 é de aproximadamente 500 pontos e a tendência nos próximos triênios também é de aumento.

Quanto ao número de docentes, o referido documento registra um total de 930 docentes atuando nos PPGEF. Destes, 649 são permanentes e a expectativa para o próximo triênio (2013/2015) é de que esse número passe para 800 docentes permanentes na PGEF. Os docentes na área são estáveis e os índices de oscilação e colaboração são de 15\% e 18\%, respectivamente. Quanto ao número total de discentes, o relatório informa que são 2816, destes: 1965 (70\%) são de mestrado e 851 (30\%) são de doutorado. Ainda sobre os discentes, $38 \%$ são autores de artigos e 31\% publicam em periódicos de estratos B1 para cima.

O índice de impacto da área de Educação Física no triênio 2001/2003 era de 0,7, no triênio 2004/2006 passou para 1,22, e no triênio de 2007/2009 foi de aproximadamente 1,89 (COSTA, 2009). É pertinente recuperar então o que disse o professor Dirceu Costa no Fórum Permanente de Pós-Graduação em Educação Física do Colégio Brasileiro de Ciências do Esporte (FPPGEF/CBCE), em Florianópolis/2011, sobre o fato de que o aumento no índice de impacto significa que a área está se fortalecendo. $\mathrm{O}$ crescimento ou não dos indicadores de produção da área, especialmente de produção intelectual e índice de impacto, repercute na grande área ${ }^{10}$.

Apesar desses dados "otimistas", observamos que os dados preocupantes também merecem atenção, uma vez que retratam a qualidade, lugares e a natureza da produção dos pesquisadores que estão sendo formados pelos PPGEF. Em relação à qualidade, apontamos o aligeiramento da formação, especialmente no mestrado, em virtude do controle do tempo médio de titulação (TMT).

[...] a compressão do tempo de conclusão, sobretudo do mestrado, comprometeu o trânsito dos alunos em um leque de disciplinas, geralmente oferecidas nos bons cursos de pós-graduação do

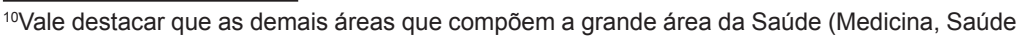
Coletiva, Farmácia, Odontologia etc.) apresentam índice de impacto acima de 2 pontos.
}

Movimento, Porto Alegre, v. 20, n. 4, p. 1563-1585, out./dez. de 2014. 
Dilemas da política científica da Educação Física ...

país. Tais disciplinas, via de regra, possibilitavam o contato dos alunos com temas diversos e literatura original, hoje praticamente impossível nos seminários de pesquisa formatadores de dissertações de curto prazo. Este é, talvez, o impacto mais notável do processo que fragilizou a formação de pesquisadores neste nível de ensino. Não se defende aqui a ausência de delimitação do tempo de titulação. Aponta-se, tão somente, a necessidade de critérios para a necessária flexibilização em nome da qualidade e do sentido formativo da pós-graduação, para além de uma certificação meramente formal (KUENZER; MORAES, 2005, p. 1349-1350).

Quando se trata de lugares, as evidências nos levam para a concentração regional e mesorregional dos PPGEF. A figura a seguir destaca tais informações:

Figura 3 - Distribuição dos Programas de Pós-Graduação em Educação Física até junho de 2013, por região geográfica

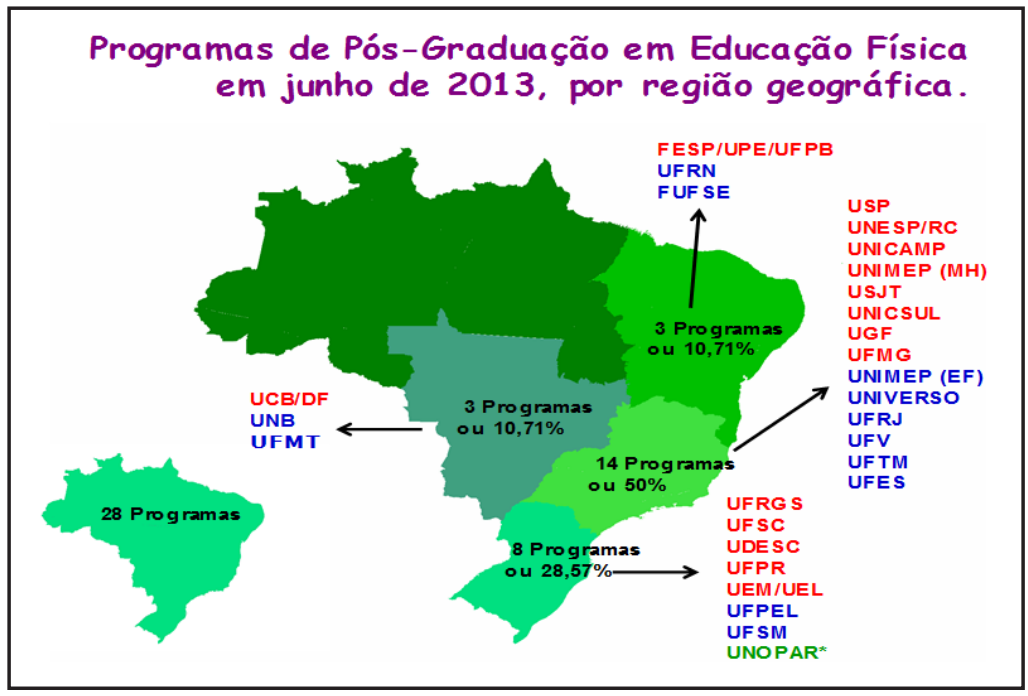

Fonte: CAPES/MEC (2013).

Legenda: Programas em vermelho: Mestrado/Doutorado; Programas em Azul: Mestrado; Programa em verde: Mestrado profissional.

Movimento, Porto Alegre, v. 20, n. 4, p. 1565-1587, out./dez. de 2014. 
No entanto, apesar desses evidentes avanços da produção científica na área e dos expressivos números de programas existentes nos últimos 36 anos, observamos alguns paradoxos. Um deles está relacionado ao desequilíbrio na distribuição geográfica dos programas de pós-graduação no contexto brasileiro, principalmente por concentrar sua localização, prioritariamente, nas regiões Sudeste e Sul do país, haja vista que 78\% dos PPGEF concentram-se nestas regiões do Brasil.

Já as regiões Norte, Nordeste e Centro-Oeste têm ficado à margem nesta distribuição desigual. Inclusive, não há até o momento nenhum programa de pós-graduação em Educação Física na região Norte.

Apesar disso, hoje, a região Nordeste já conta com três mestrados em Educação Física, criados recentemente, um em 2008 pela Fundação Universidade de Pernambuco (FESP/UPE) em convênio com a Universidade Federal da Paraíba (UFPB), outro, em 2010, pela Universidade Federal do Rio Grande do Norte (UFRN) e o mais recente criado pela FUF Sergipe.

Na região Centro-Oeste, também há dois programas de pósgraduação em Educação Física: um mais antigo, criado em 1999 pela Universidade Católica de Brasília (UCB/DF), outro criado em 2006 pela Universidade de Brasília (UNB) e o mais recente pela Universidade Federal de Mato Grosso (UFMT).

Ainda sobre a distribuição geográfica dos programas de pós-graduação no contexto brasileiro, é oportuno fazermos duas observações: 1) em que pese esta distribuição ser desigual em todo o SNPG, a área de Educação Física apresenta índices mais desiguais do que outras áreas (Educação, por exemplo) e do que o próprio SNPG como um todo; e 2) como podemos observar, no quadro 1, a seguir, o potencial instalado na região Nordeste, por exemplo, parece que não tem sido bem trabalhado pela área no processo de criação de novos programas na região. 
Dilemas da política científica da Educação Física ...

Quadro 1 - Dados da região Nordeste (cursos, professores e áreas de titulação dos doutores da região)

\begin{tabular}{|c|c|c|c|c|c|c|c|c|}
\hline \multirow{2}{*}{ N. } & \multirow{2}{*}{ Estado } & \multirow{2}{*}{$\begin{array}{c}\text { Cursos } \\
\text { em } \\
\text { Atividade }\end{array}$} & $\begin{array}{c}\text { Número } \\
\text { de Prof. } \\
\text { Mestres e } \\
\text { Doutores }\end{array}$ & $\begin{array}{c}\text { Número de } \\
\text { Prof. com } \\
\text { Mestrado }\end{array}$ & $\begin{array}{c}\text { Número de } \\
\text { Prof. com } \\
\text { Doutorado }\end{array}$ & \multicolumn{3}{|c|}{$\begin{array}{c}\text { Áreas de Titulação } \\
\text { dos doutores }\end{array}$} \\
\cline { 5 - 11 } & Alagoas & 10 & 49 & 33 & $\mathbf{1 6}$ & 12 & 2 & 2 \\
\hline 2 & Bahia & 37 & 111 & 72 & $\mathbf{3 4}$ & 11 & 19 & 4 \\
\hline 3 & Ceará & 23 & 82 & 60 & $\mathbf{2 2}$ & 6 & 8 & 8 \\
\hline 4 & Maranhão & 8 & 32 & 22 & $\mathbf{1 0}$ & 1 & 3 & 6 \\
\hline 5 & Paraíba & 7 & 82 & 35 & $\mathbf{4 7}$ & 22 & 7 & 18 \\
\hline 6 & Pernambuco & 19 & 102 & 62 & $\mathbf{4 0}$ & 16 & 5 & 19 \\
\hline 7 & Piauí & 7 & 8 & 7 & $\mathbf{1}$ & 0 & 1 & 0 \\
\hline 8 & Rio G. do Norte & 6 & 37 & 16 & $\mathbf{2 1}$ & 4 & 9 & 8 \\
\hline 9 & Sergipe & 6 & 46 & 33 & $\mathbf{1 3}$ & 1 & 3 & 9 \\
\hline & Total & $\mathbf{1 2 3}$ & $\mathbf{5 4 9}$ & $\mathbf{3 4 0}$ & $\mathbf{2 0 4}$ & $\mathbf{7 3}$ & $\mathbf{5 7}$ & $\mathbf{7 4}$ \\
\hline
\end{tabular}

Fonte: Sánchez Gamboa (2013) e MEC (2010).

No que diz respeito à natureza, apesar da melhoria no número de doutores titulados a partir de 2007, a área forma poucos doutores diante da demanda dos cursos de graduação e as metas previstas pelo Plano Nacional de Educação para o período de 2011 a 2020 (PNE/2011-2020).

Dentre as metas estabelecidas no PNE, vale destacar o que tem sido recomendado para a educação superior e pós-graduação stricto sensu. A meta 13 diz: elevar a qualidade da educação superior pela ampliação da atuação de mestres e doutores nas instituições de educação superior para $75 \%$, no mínimo, do corpo docente em efetivo exercício, sendo, do total, $35 \%$ doutores. Já a meta 14: elevar gradualmente o número de matrículas na pósgraduação stricto sensu de modo a atingir a titulação anual de 60 mil mestres e 25 mil doutores. Estratégias 14.8: ampliar a oferta de programas de pós-graduação stricto sensu, especialmente o do doutorado, nos campi novos abertos no âmbito dos programas de expansão e interiorização das instituições superiores públicas (BRASIL, 2010).

Movimento, Porto Alegre, v. 20, n. 4, p. 1565-1587, out./dez. de 2014. 
Diante dessas metas previstas, o quadro a seguir busca demonstrar como tem se configurado, em julho de 2013, o número de cursos de Educação Física em atividade no Brasil.

Quadro 2 - Cursos de Educação Física em atividade no Brasil em julho de 2013

\begin{tabular}{|c|c|c|}
\hline N. & Estado & $\begin{array}{c}\text { Cursos de Educação Física em } \\
\text { Atividade } \\
\text { (Lic e Bac-Pres e EaD) }\end{array}$ \\
\hline 1 & Acre & 5 \\
\hline 2 & Alagoas & 13 \\
\hline 3 & Amazonas & 41 \\
\hline 4 & Amapá & 4 \\
\hline 5 & Bahia & 61 \\
\hline 6 & Ceará & 29 \\
\hline 7 & Distrito Federal & 25 \\
\hline 8 & Espírito Santo & 27 \\
\hline 9 & Goiás & 31 \\
\hline 10 & Maranhão & 9 \\
\hline 11 & Minas Gerais & 161 \\
\hline 12 & Mato Grosso do Sul & 24 \\
\hline 13 & Mato Grosso & 24 \\
\hline 14 & Pará & 13 \\
\hline 15 & Paraíba & 10 \\
\hline 16 & Pernambuco & 25 \\
\hline 17 & Piauí & 16 \\
\hline 18 & Paraná & 91 \\
\hline 19 & Rio de Janeiro & 88 \\
\hline 20 & Rio Grande do Norte & 14 \\
\hline 21 & Rondônia & 10 \\
\hline 22 & Roraima & 4 \\
\hline 23 & Rio Grande do Sul & 75 \\
\hline 24 & Santa Catarina & 71 \\
\hline 25 & Sergipe & 7 \\
\hline 26 & São Paulo & 337 \\
\hline 27 & Tocantins & 11 \\
\hline \multicolumn{2}{|r|}{ Total } & 1226 \\
\hline
\end{tabular}

Fonte: MEC (2013).

Movimento, Porto Alegre, v. 20, n. 4, p. 1563-1585, out./dez. de 2014. 
Dilemas da política científica da Educação Física ...

A partir desse panorama, podemos fazer um breve exercício de aritmética, por exemplo:

Considerando 1200 cursos de graduação em Educação Física com 10 docentes por curso, teremos um total de 12000 docentes. Logo, 35\% desse total com o título de doutor, conforme indicação do PNE/2011-2020, são 4200 docentes/doutores;

Considerando ainda que, até 2009, a área havia titulado 420 doutores, e que a PGEF no triênio 2007-2009 titulou 135 doutores, teremos um crescimento de $33,33 \%$ a mais que o triênio anterior (2004-2006). Podemos pressupor que, face ao aumento no número de cursos de doutorado no triênio 2010/2012 e a previsão de crescimento nos triênios seguintes, a PGEF poderá manter, a partir dos dados do triênio 2007/2009, um ritmo de crescimento trianual de $50 \%$ no número de doutores titulados.

Assim sendo, é possível visualizarmos o seguinte quadro:

Quadro 3 - Demonstrativo do número de doutores titulados nos triênios 20072009 e 2010-2012, e projeções para os triênios seguintes

\begin{tabular}{|c|c|c|c|c|c|c|c|c|}
\hline Triênios & $07 / 09$ & $10 / 12$ & $13 / 15$ & $16 / 18$ & $19 / 21$ & $22 / 25$ & $26 / 29$ & Total \\
\hline Drs. Tit. & 135 & 203 & 305 & 458 & 687 & 1030 & 1545 & $\mathbf{4 7 8 3}$ \\
\hline
\end{tabular}

Fonte: CAPES/MEC (2013).

Logo, a partir dos dados dos triênios 2007-2009 e 2010-2012, e considerando os melhores dos horizontes para o crescimento da PGEF, a perspectiva é de que a área atenda à meta do PNE quase uma década depois do previsto pelo plano ${ }^{11}$.

A partir da observação de alguns estudos realizados na área, podemos afirmar que os critérios de avaliação não atendem à diversidade da área de conhecimento "EF". E, nesse sentido, a avaliação consubstanciada em

\footnotetext{
${ }^{11}$ Reiteramos que este exercício não considera uma série de elementos de projeção, como crises financeiras, contingenciamento de recursos, conflitos sociais, etc.
}

Movimento, Porto Alegre, v. 20, n. 4, p. 1565-1587, out./dez. de 2014. 
critérios produtivos de viés analítico apresenta uma contradição, pois possibilita, de um lado, o desenvolvimento de uma subárea, a Biodinâmica, e, de outro, causa a estagnação, submissão (e provável desaparecimento) das outras subáreas, a pedagógica e a sociocultural ${ }^{12}$.

Nesse sentido, observamos que a política científica da área mediada pelos PPGEF via área 21 tem baixa aderência à política nacional da pós-graduação, especialmente com relação ao eixo estratégico da Educação Básica, pois a avaliação da área não reconhece a diversidade desta.

\section{Sobre os dilemas dA Política científica da EducaçÃo Fí́SICA NO BRASIL}

Em virtude da política de avaliação da área 21, muitos professores doutores da área de Educação Física, especialmente das subáreas sociocultural e pedagógica, não são incorporados pelos PPGEF e/ou junto com seus pares não conseguem aprovar a "Apresentação de Propostas de Cursos Novos (APCNs)" de suas instituições, fazendo com que muitos desses professores, pesquisadores reconhecidos na área, evadam para programas de pós-graduação em outras áreas do conhecimento, como: Educação, Sociologia, etc. - Fenômeno da "Evasão de cérebros" e de "trava das APCNs ${ }^{13}$ " diferente do modelo vigente.

Nesse sentido, é oportuno recuperar a fala de Alexandre Vaz, FPPGEF/CBCE de 2011, na mesa que tratou dos periódicos científicos, momento no qual se referiu aos professores Antônio Jorge G. Soares e Carmem Lúcia Soares, e indicou a tendência de extinção dos grupos das humanidades no âmbito da PGEF.

Nesse sentido, os quadros 1 e 4 destacam algumas evidências dessa tendência na área.

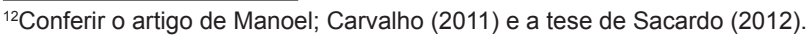

${ }^{13}$ Conforme apresentado no relatório do Seminário de Acompanhamento da Área 21, realizado em Brasília, em dezembro de 2012, a taxa de reprovação das APCNs na área, no período de 2009 a 2012, foi de $70 \%$.
}

Movimento, Porto Alegre, v. 20, n. 4, p. 1563-1585, out./dez. de 2014. 
Dilemas da política científica da Educação Física ...

Quadro 4 - Docentes da área da Educação Física que estão atuando em Programas de Pós-Graduação em Educação

\begin{tabular}{|c|c|c|}
\hline Região & $P P G-I E S$ & NOME DO DOCENTE \\
\hline \multirow{9}{*}{ Sudeste } & \multirow{4}{*}{ FAE/PPGE - UFMG } & Andrea Moreno \\
\hline & & Marcus Aurélio Taborda \\
\hline & & Meily Assbú Linhales \\
\hline & & Tarcísio Mauro Vago \\
\hline & PPGE/FACED - UFU & Gabriel Humberto Munoz Palafox \\
\hline & FAE/PPGE - UNICAMP & Carmem Lúcia Soares \\
\hline & \multirow{2}{*}{ PPGE - UFRJ } & Antônio Jorge Gonçalves Soares \\
\hline & & Victor Andrade de Melo \\
\hline & PPGE - UFSCAR & Luiz Gonçalves Junior \\
\hline \multirow{6}{*}{ Nordeste } & \multirow{6}{*}{ PPGE - UFBA } & Celi Taffarel \\
\hline & & Augusto Cesar Rios Leiro \\
\hline & & Claudio Lira Santos Junior \\
\hline & & Elza Margarida de Mendonça Peixoto \\
\hline & & Maria Cecília de Paula Silva \\
\hline & & Pedro Rodolfo Jungers Abid \\
\hline \multirow{3}{*}{$\begin{array}{c}\text { Centro- } \\
\text { Oeste }\end{array}$} & \multirow{2}{*}{ PPGE - UFG } & Régis H. dos Reis Silva \\
\hline & & Rubia-mar Nunes Pinto \\
\hline & PPGE - PUC/GO & Paulo Roberto Veloso Ventura \\
\hline \multirow{3}{*}{ Sul } & \multirow{2}{*}{ PPGE - UFSC } & Jaison José Bassani \\
\hline & & Alexandre Fernandez Vaz \\
\hline & PPGE - UFPR & Marcus Aurélio Taborda de Oliveira \\
\hline \multirow{2}{*}{ Sudeste } & \multirow{2}{*}{ FAE/PPGE - UFMG } & Andrea Moreno \\
\hline & & Marcus Aurélio Taborda \\
\hline
\end{tabular}

Fonte: CAPES/MEC (2013).

Muitos professores de Educação Física, principalmente das regiões Norte, Nordeste e Centro-Oeste, continuam seus estudos em nível de pós-graduação stricto sensu na área de Educação Física fora do país ou em outras áreas do conhecimento, especialmente nas ciências humanas e sociais.

Desse modo, muitos professores doutores que atuam nos cursos de graduação em Educação Física são formados nas mais diversas áreas e regiões do país - explicitando a dependência técnicocientífica da área em relação a outras áreas do conhecimento, o que inevitavelmente limita o desenvolvimento da Educação Física brasileira.

Movimento, Porto Alegre, v. 20, n. 4, p. 1565-1587, out./dez. de 2014. 
Nesse sentido, muitos professores de Educação Física das regiões Sul e Sudeste também continuam seus estudos em nível de pós-graduação stricto sensu em outras áreas do conhecimento pela não identificação com o perfil político-epistemológico dos PPGEF das referidas regiões.

Além de tudo isso, é comum muitos professores de Educação Física, futuros pesquisadores da área, procurarem uma segunda formação (ciências sociais, pedagogia, filosofia, etc.), pois não visualizam a possibilidade de desenvolverem pesquisas na área 21 .

Enfim, diante dos indicadores apresentados, podemos dizer que os representantes da área de Educação Física, particularmente os PPGEF via área 21, aprenderam muito bem a lição das diretrizes da CAPES no que se refere à internacionalização da produção via avaliação competitiva dos PPGEF e das APCNs. Já não podemos dizer que a nossa área e os referidos atores estudaram com o mesmo afinco as diretrizes da CAPES, no que se refere à indução do eixo estratégico Educação Básica, na PGEF. Até porque considerar a mudança da estratificação das Revistas - RBCE; Movimento; e Educação Física da UEM; como ação de indução da subárea pedagógica na política de avaliação da área 21, parece-nos muito pouco para o "tsunami" que tem sido as ações da CAPES, em especial a indução à Educação Básica no âmbito da PG e da Universidade brasileira.

Mas, enfim, o que fazer?

\section{Algumas considerações (MAS, enfim, o que fazer?)}

Diante do quadro apresentado e no intuito de instigar o debate, apontamos algumas possibilidades que visualizamos para o enfrentamento político da questão no âmbito da pós-graduação da área de Educação Física e suas prováveis consequências:

Tensionar a área 21 - Consolidar os fóruns de PGEF, particularmente do $\mathrm{CBCE}$, incluindo novos atores e apresentando

Movimento, Porto Alegre, v. 20, n. 4, p. 1563-1585, out./dez. de 2014. 
novos critérios de avaliação (o PNPG/2011-2020) sinaliza nesse sentido, por exemplo, o eixo 3 indica "o aperfeiçoamento da avaliação e sua expansão para outros segmentos do sistema de C,T\&I". Nesse sentido, propomos ao CBCE a criação de uma comissão para discutir novos critérios de avaliação, que vão ao encontro dos eixos estratégicos do PNPG, particularmente aqueles referentes à Educação Básica, tendo em vista a vinculação político-epistemológica da nossa área com a intenção pedagógica (BRACHT, 2006) e/ou ato pedagógico (SÁNCHEZ GAMBOA, 2007);

Adaptar-se à área 21 - Adaptação, pois se trata da manutenção do atual modelo de PGEF, qual seja 50\% biodinâmica, 30\% sociocultural e $20 \%$ pedagógica. Isso implica na contratação imediata e/ou a médio e longo prazo de professores/pesquisadores formados nas regiões Sul e Sudeste, que migram e/ou migrarão para as regiões Norte, Nordeste e Centro-Oeste, objetivando emprego e a criação da PGEF nestas regiões, sob uma lógica de manutenção do modelo de PGEF citado.

Consentir com a política oficiosa de "evasão de cérebros" para a área 38 (Educação) e a criação de subáreas de Educação Física no interior daquela.

Uma parte significativa da área migrar ou submeter suas APCNs à área 46 de ensino ${ }^{14}$, principalmente as instituições que, historicamente, têm interesse pelos espaços de educação formal (escola) e não formal como referência empírica da pesquisa em Educação Física.

Por fim, ponderamos que as duas primeiras situações são limitadas pela própria aceitação da diversidade da Educação Física na área 21. A terceira também é problemática, pois se trata mais de ações individuais e/ou de pequenos grupos de professores de

\footnotetext{
${ }^{14}$ Nesse sentido, a título de observação, é oportuno registrar que, no XVIII CONBRACE e V CONICE, identificamos 30 trabalhos com os títulos relacionados ao tema PIBID e $58 \mathrm{com}$ os resumos relacionados a esta temática, que, de acordo com nossas análises, faz parte do "PACOTE CAPES PARAA EDUCAÇÃO BÁSICA BRASILEIRA".
}

Movimento, Porto Alegre, v. 20, n. 4, p. 1565-1587, out./dez. de 2014. 
Educação Física que vão para a área 38, logo, não representa a área de Educação Física como um todo. Já a última, embora seja problemática pelo viés existente (realismo empírico - comum a todas as outras), parece apresentar uma nova possibilidade que sem contrariar a natureza epistemológica da área, no plano político-acadêmico, sinaliza para a possibilidade de alteração na correlação de forças da área acadêmica da Educação Física e quem sabe poderá imprimir uma nova dinâmica na política científica da Educação Física brasileira.

Dilemmas of science policy in Brazil's Physical Education in
times of academic productivism
Abstract: The essay aims to conduct a brief discussion on the
political dilemmas faced by Brazil's science policy for physical
education in times of academic productivism, particularly the
one developing in the context of "stricto sensu" post-graduate
programs. After an overview of Brazilian Graduate Studies, we look
at reconfiguration process of CAPES and Brazilian universities in
recent years, where we point out "optimistic" indicators of science
policy of postgraduate programs in Physical Education as well as
troubling aspects in the area. Given that situation and in order to
raise debate, we point out some possibilities in Physical Education.
Keywords: Science Policy. Physical education. Academic
productivism.

Los dilemas de la Educación Física científica política en
tiempos de productivismo académico brasileño
Resumen: La intención de este trabajo es analizar brevemente
los dilemas políticos de la Educación Física científica en tiempos
de productivismo académico brasileño, en especial aquel que
se desarrolla en el contexto de postgrado stricto sensu. En el
panorama de los cursos de postgrado, visualizamos el proceso de
reconfiguración de la Capes y la universidad brasileña en los últimos
años, donde se destacan los indicadores de la política optimista de
los programas de postgrado científicos en la Educación Física -
PPGEF, así como los aspectos problemáticos de la zona. Frente a
esta situación, y con el fin de provocar el debate, se ha señalado
algunas posibilidades de la Educación Física.
Palabras clave: Ciencia política. La educación física. El
productivismo académico.

Movimento, Porto Alegre, v. 20, n. 4, p. 1563-1585, out./dez. de 2014. 
Dilemas da política científica da Educação Física ...

\section{REFERÊNCIAS}

AGENCIA FAPESP. Pesquisa de qualidade, não de quantidade. 2013. Disponível em <http://agencia.fapesp.br/17608\#.Ufe5ZRgjxlQ.email>. Acesso em: 27 jul. 2013.

ÁVILA, A. B. A pós-graduação em Educação Física e as tendências na produção de conhecimento: o debate entre realismo e anti-realismo. Tese (Doutorado em Educação) - Centro de Ciências da Educação, Universidade Federal de Santa Catarina, Florianópolis, 2008.

BRACHT, V. Por uma política científica para a educação física com ênfase na pósgraduação. In: FÓRUM NACIONAL PERMANENTE DE PÓS-GRADUAÇÃO EM EDUCAÇÃO FÍSICA, 2006, Campinas. Disponível em: <http://www.cbce.org.br/ aconece/materia.asp?id=312>. Acesso em: 8 nov. 2007.

BRASIL. Ministério da Educação. Coordenação de Aperfeiçoamento de Pessoal de Nível Superior. Plano Nacional de Educação (PNE): Projeto de Lei - $\mathrm{N}^{\circ}$. 8035/2010. Disponível em: <http://portal.mec.gov.br/index.php?option=com content\&id=16478\&ltemid=1107>. Acesso em: 22 dez. 2010.

BRASIL. Ministério da Educação. Coordenação de Aperfeiçoamento de Pessoal de Nível Superior. Plano Nacional de Pós-Graduação: PNPG 2011-2020. Brasília, DF: CAPES, 2011. Disponível em: <http://www.capes.gov.br/sobre-a-capes/planonacional-de-pos-graduacao/pnpg-2011-2020>. Acesso em: 13 ago. 2011.

CHAUÍ, M. A universidade pública sob nova perspectiva. Disponível em: <http:// www.anped.org.br>. Acesso em: 12 nov. 2003.

CHESNAIS, F. O capital portador de juros: acumulação, internacionalização, efeitos econômicos e políticos. In: CHESNAIS, F. (Org.). A finança mundializada. São Paulo: Boitempo, 2005.

COORDENAÇÃO DE APERFEIÇOAMENTO DE PESSOAL DE NÍVEL SUPERIOR/MINISTÉRIO DA EDUCAÇÃO (CAPES/MEC). Cadernos de indicadores. Disponível em: <http://conteudoweb.capes.gov.br/conteudoweb/ CadernoAvaliacaoServlet> Acesso em: 22 maio 2013.

COORDENAÇÃO DE APERFEIÇOAMENTO DE PESSOAL DE NÍVEL SUPERIOR (CAPES). Seminário de acompanhamento. Representação de Área/Educação Física. Brasília, DF, 2012. Disponível em:

<http://www.capes.gov.br/component/content/article/44-avaliacao/4666-educacaofisica>. Acesso em: 22 maio 2013.

COSTA, D. Indução dos programas de pós-graduação em Educação Física. In: FÓRUM PERMANENTE DE PÓS-GRADUAÇÃO EM EDUCAÇÃO FÍSICA DO COLÉGIO BRASILEIRO DE CIÊNCIAS DO ESPORTE, 2011, Florianópolis. Disponível em:<http://www.cbce.org.br/br/pos/videosfppegef4.asp>. Acesso em: 26 maio 2013.

Movimento, Porto Alegre, v. 20, n. 4, p. 1565-1587, out./dez. de 2014. 
COSTA, D. Palestra do Prof. Dr. Dirceu Costa (Coordenador da Área 21). In: Fórum Permanente de Pós-Graduação em Educação Física do Colégio Brasileiro de Ciências do Esporte, 2009, Florianópolis. Disponível em: <http://www.cbce.org.br/ br/acontece/materia.asp?id=594>. Acesso em: 26 maio 2013.

FERREIRA, A. B. H. Dilema. In: Dicionário Aurélio da língua portuguesa. 5. ed. Curitiba: Positivo, 2010.

KUENZER, A. Z.; MORAES, M. C. M. Temas e tramas na pós-graduação em educação. Educação e Sociedade, Campinas, v. 26, n. 93, p. 1341-1362, set./ dez. 2005. Disponível em:<http://www.scielo.org.br>. Acesso em: 13 mar. 2005.

LALANDE, A. Vocabulário técnico e crítico da filosofia. 3. ed. São Paulo: Martins Fontes, 1999.

MANOEL, E. J.; CARVALHO, Y. M. Pós-Graduação na Educação Física Brasileira: a atração (fatal) para a biodinâmica. Educação e Pesquisa, São Paulo, v. 37, n. 2, p. 389-406, ago. 2011.

MINISTÉRIO DA EDUCAÇÃO (MEC). Cursos de Educação Física em atividade no Brasil. Disponível em: <http://emec.mec.gov.br>. Acesso em: maio 2010.

MINISTÉRIO DA EDUCAÇÃO (MEC). Cursos de Educação Física em atividade no Brasil. Disponível em: <http://emec.mec.gov.br>. Acesso em: 27 jul. 2013.

MORAES, M. C. M. de. Avaliação na pós-graduação brasileira: novos paradigmas, antigas controvérsias. In: BIANCHETTI, L.; MACHADO, A. M. N. (Org.). A bússola do escrever: desafios e estratégias na orientação de teses e dissertações. Florianópolis: Ed. UFSC; São Paulo: Cortez, 2006. p. 187-214.

MORAES, M. C. M. de. Iluminismo às avessas como contexto da pós-graduação no Brasil. Educação Unisinos, São Leopoldo, v. 5, n. 9, p. 79-101, jul./dez. 2004.

MORAES, M. C. M. de. Recuo da teoria: dilemas na pesquisa em educação. Revista Portuguesa de Educação, Braga, v. 14. n. 1, p.7-25, 2001.

NEVES, L. M. W.; PRONKO, M. A. O mercado do conhecimento e o conhecimento para o mercado: da formação para o trabalho complexo no Brasil contemporâneo. Rio de Janeiro: EPSJV, 2008.

OURIQUES, N. Ciência e pós-graduação na Universidade brasileira. In: RAMPINELLI, W. J.; OURIQUES, N. Crítica à razão acadêmica: reflexão sobre a universidade contemporânea. Florianópolis: Insular, 2011. p. 73-107.

SACARDO, M. S. Estudo bibliométrico e epistemológico da produção científica em Educação Física na Região Centro-Oeste do Brasil. 2012. $255 f$. Tese (Doutorado em Educação) - Programa de Pós-Graduação em Educação, Universidade Federal de São Carlos, São Carlos, 2012.

SÁNCHEZ GAMBOA. S. Á. Epistemologia da Educação Física: as inter-relações necessárias. Maceió: EdUFAL, 2007. 165 p. 
SÁNCHEZ GAMBOA, S. Á. Produção do conhecimento em educação física: impacto do sistema de pós-graduação das regiões sul e sudeste do Brasil na formação e produção de mestres e doutores que atuam nas instituições de ensino superior da região nordeste. 2013. 30f. Relatório parcial do projeto temático FAPESP (processo n. 2012/50019-7).

SILVA, R. H. dos R. Tendências teórico-filosóficas das teses em educação especial desenvolvidas nos cursos de doutorado em educação e educação física do estado de são paulo (1985-2009). 2013. 390f. Tese (Doutorado em Educação) - Departamento de Filosofia e História da Educação, Unicamp, Campinas/SP, 2013. Disponível em: <http://www.bibliotecadigital.unicamp.br/ document/?code $=000907086>$. Acesso em: 04 fev. 2014.

VAZ, A. Periódicos em Educação Física. In: FóRUM PERMANENTE DE PósGRADUAÇÃO EM EDUCAÇÃO FÍSICA DO COLÉGIO BRASILEIRO DE CIÊNCIAS DO ESPORTE, 2011, Florianópolis. Disponível em: <http://www.cbce. org.br/br/pos/videosfppegef4.asp>. Acesso em: 26 maio 2013.

VELHO, L. Conceitos de Ciência e a Política Científica, Tecnológica e de Inovação. Sociologias, Porto Alegre, v. 13, n. 26, p. 128-153, jan./abr. 2011. 